\title{
Technical Change and the Un/Troubling of Gendered Ageing in Healthcare Work
}

Susan Halford, University of Southampton, UK

Ann Therese Lotherington, University of Tromso, Norway

Aud Obstfelder, University of Tromsø, Norway

Natalia Kukarenko, Northern Arctic Federal University, Russia

Corresponding authorsusan.halford@soton.ac.uk

Paper accepted for publication in Gender, Work and Organization (subject to publisher's copy-editing)

Uploaded $15^{\text {th }}$ January 2015 


\section{Introduction}

The future of older workers has been of increasing concern for individuals, employers and governments alike over recent years (Loretto and Duncan 2004). Specifically, the pensions' crisis means that most of us must work longer to support ourselves into old age whilst birth rate decline in the West demands extended working lives to meet long-term labour market needs (Parliamentary Office of Science and Technology 2011; CIPD 2012). Nonetheless, it is clear that there remain significant challenges to achieving this and that these take specifically gendered forms. Women's labour market participation in later life continues to be shaped by gendered divisions of labour related to caring responsibilities for both elderly relatives and children (Loretto et al 2005; Phillipson and Smith 2005; Evandrou and Glaser 2007; Brooke 2009) and exacerbated by limited provision of flexible working hours for older workers (TUC 2013). Furthermore, we know that age-based stereotyping and discrimination are gendered and often especially severe for women (Duncan and Loretto 2004; Moore 2009; Irni 2009). Nonetheless, to date, employers and policy makers appear poorly equipped to address these gendered ageing inequalities, not least because existing legislative and organizational interventions recognise gender and age separately, rather than addressing their interplay (Smith 2012). Meanwhile, related theoretical developments are beginning to offer a rich and promising source of understanding as the trajectory of conceptualisation moves from a focus on either gender or age, through additive notions of 'double jeopardy' to insistence on the intersectionalities of gender and ageing as these emerge in specific spaces, places and times (Krekula 2012).

In this context, our aim is to examine the interplay of gender, age and technology at work specifically in healthcare - where new technologies are reshaping work in multiple and profound ways. Previous studies have shown that - in general - older workers are more likely to take early retirement where there is rapid technological change (Bartel and Sicherman 1993; Robertson 2000; Friedberg 2003; Aubert et al 2006) and that workplace technologies, and the changes with which they are associated, are often highly gendered (Cockburn 1983; Wajcman 2004; Authors 2010). This poses some important questions for the retention of older workers and for our understanding of gendered ageing at work more broadly. To address these, our paper draws together and extends the largely separate insights from previous research with the help of a theoretical framework drawn from feminist theory, critical gerontology and Science and Technology Studies. At its heart, this perspective insists on an anti-essentialist approach to gender and age emphasising their contingent intra-action (Barad 2003) in the sociomaterial practices of everyday life. This is not about age, gender or technology per se. Rather it is to transcend such a priori assumptions and clear cut distinctions (Wolkowitz 2005). Following Irni's (2008) suggestion, we turn the question on its head: instead of asking 'how does technological change impact on older men and women at work?' we ask 'how, where and when is gendered ageing produced in contexts of rapid technological change?'

In what follows, we elaborate on this theoretical framing and use it to explore the findings of a new empirical study of nursing, where a 'perfect storm' is brewing at the interface of rising 
demand, cuts in public spending and a rapidly ageing workforce, and unusually high rates of early retirement (JRF 2003; National Nursing Research Unit 2007; Victoria Department of Health 2010). These demographic conditions exacerbate the already intractable challenge facing healthcare systems: how to meet rising demand within restricted expenditure? The pursuit of accelerated technological innovation has often been positioned as key to the solution (UK Department of Health 2002, 2012; Norweigan Ministries 2012) but it is unclear if and how this might impact on the retention of an ageing and gendered workforce. Our case study is taken from Norway, where successive governments have invested heavily in technological innovation, not least in healthcare where new landscapes for the delivery of care are transforming healthcare work (Authors 2009; 2010). Underpinned by our theoretical framework we explore what this means for gendered ageing as this emerges in the interplay of political and organizational processes, everyday working practices and through individual circumstances and actions. We conclude with a discussion of the wider theoretical and practical implications of our approach and findings.

\section{Theorising Gender, Age and Technology at Work}

Recent debates in critical gerontology have drawn on feminist theory to reconceptualise relations between gender and age. In particular, there has been a move away from notions of 'double jeopardy' (Dowd and Bengston 1978), which treat gender and age as separate and discrete sources of inequality that, added together, produce accumulated disadvantage; towards an understanding that gender and age may be co-produced (Krekula 2007): that is to say, each may modify the other to produce distinctive outcomes not accountable for by either category independently. In the emergent genealogy of feminist scholarship on intersectionalty (Lykke 2010) this claim is elaborated in a variety of ways. Originally, Crenshaw (1995) likened intersectionality to a cross-roads - in that instance between gender and race - as a political move to push for interventions beyond the established repertoire of feminist or anti-racist actions (Staunæs, 2003). Similarly, and directly relevant to our focus here, McMullin (2000; and with Berger 2006) proposes a critical perspective on diversity and ageing that theorises gender, race, class and age as analytically distinct sets of power relations that 'come together' in particular empirical contexts such that it is impossible to know in advance which will be more or less important. More recently however, the implications of 'intersectionality' have been extended beyond this metaphor, which rests on the identification of structural categories that exist both independently and objectively prior to any empirical intersections, to suggest alternative conceptualisations of these categories themselves (Lykke 2012). Drawing our inspiration from these more poststructuralist accounts, there are three key points of importance for us here.

First, it is no longer possible to identify any 'pure' categories such as gender or age. Rather that we must explore the 'complex mutual saturation and toning among the categories' (Søndergard 2005; 192) as their 'constitutive dynamics move, transform and work on each other' (ibid). Thus we might more accurately speak of their intra-action (Barad 2003) or, it follows, 'intrasectionality' (see also McCall 2005). Second, whilst political interventions may require claims about fixed structures and inequalities, we understand categories and their intersectionalities as performative (Butler 1990): the outcome of practices rather than the inherent attributes of individuals or inevitable consequence of reified structures that determine the actions of individuals. Third, we cannot know in advance what the outcome of gendered ageing will be, and these outcomes may be both 
multiple (Joyce and Mamo 2006) and contradictory (Biggs 2004). As Staunæs (2003) suggests, before we assume that well known categories will explain particular outcomes, we should 'wait and see' what the outcomes actually are. One important rendering of this point is that whilst 'double jeopardy' assumes that gendered ageing generates multiple disadvantages for women, the empirical evidence is ambivalent, sometimes showing the advantages that gendered ageing can bring for some women, compared with some men (Arber et al 2003). Of course, no-one is suggesting that we create everyday practices entirely under conditions of our own choosing: as Butler (1995) has argued, these are shaped inter alia by the repetitive citation of powerful discourses and regulatory norms as well as by materialities, including embodied circumstances. Nonetheless, following this more poststructural interpretation, we suggest that it is in the practices that are negotiated in these conditions that specific iterations of gendered ageing are produced.

Turning our attention more specifically to new technologies in the workplace, this framework helps to account for the variety of empirical findings of relevance here. A number of studies show that older workers are more likely to take early retirement in organizations undergoing rapid technological change, but the processes in play are complicated. For example, Friedberg (2003) finds that older workers are less likely to invest in necessary digital skills but that this depends on proximity to retirement. For those close to retirement, the additional investment may not seem 'worth it' and so they may take early retirement instead. However, those who do invest in new skills retirement may postpone retirement. Similarly, Robertson (2000) shows that whilst technological change influenced early retirement, this was not explained by the demands of acquiring new skills, but rather by the deskilling effects of new technologies and reduced work satisfaction. Similarly, Dellve et al (2003) show that early retirement is highest in conditions of technical change where organizational support for older workers is lowest. In these cases, it is not technology or age per se that produces early retirement but the organization of technology in particular work and workplace settings that produces age or, at least, a feeling of being out of step with the organization that may be described as 'feeling old'.

Other studies have shown that ageing emerges in specific intra-actions with gender and technology and not in predetermined ways. Some counter-intuitive examples illustrate this point. Contrary to common associations of masculinity with technology, Eriksson-Zetterquist and Knights' (2004) study of technological change in two different organizations (a school and a high technology business) found that older men struggled most with change. This was linked partly to lack of new skills; partly to concerns about the wider organizational changes that technological innovation heralded; and also to broader cultural and social associations as older men resisted the association of new technologies with '... hackers, 'computer nerds' and women' (ibid; p.203). Similarly, Brooke (2009) found that older men in the IT industry are marginalised '.. winnowed out of the "technical play" that are customarily associated in the industry with "young masculinity" (p.247), which in this case meant under 30.

In short, on both theoretical and empirical grounds we have good reason to move beyond fixed assumptions about the relations between gender, ageing and new technologies. It is not that older people are simply 'bad' at technology; or that men are simply 'good' at it. Indeed, our theoretical framework suggests that it is the other way around: to be good at technology is to be youthful and, more masculine than feminine: these are performances that produce rather than reflect 
gendered ageing in specific contexts. This point is well supported by studies of women working in the Information Technology (IT) sector, which attest to the difficulties that they may face in negotiating femininity at work (Adam et al 2006). It is not being a woman per se that is the problem. The point is that femininity appears as a problematic category in an industry that is dominated by men, masculine cultural associations and a work-life balance (or lack thereof) more associated with masculinity. Similarly, research on ageing suggests that it is the performance of 'being young' that makes ageing acceptable in a 'world defined by youth' (Biggs 2004; 52). As Calestani and Slevin (2006) argue '... those who remain active are not old' (p.4), a point that has particular resonance in relation to paid work per se, not associated with old age, but which may also vary between workplaces (Brooke 2009).

Throughout these accounts of gendered ageing in relation to technology at work, it is notable that the technologies themselves remain a rather unarticulated presence. Certainly no deterministic associations are made with particular innovations but neither is the intra-action of specific innovations with gendered ageing explored. In short, it seems as if the dynamics of gendered ageing are played out on the neutral canvas of new technologies, which are represented as homogenous and inert bearers of these dynamics. Whilst the social construction of technology is well developed as a principle within Science and Technology Studies (STS) (see Mackenzie and Wacjman 1999) it is also important to note that STS has increasingly come to emphasise the part that particular devices themselves might play in producing distinctive outcomes. This is not to say that particular technologies have inherent properties with knowable effects. It is to say that the affordances of particular technologies matter - they are not infinitely mutable - and more importantly, as Actor Network Theory insists, it is in contingent combinations of human and non-human actors that social outcomes are produced (Latour 2005). Whilst Actor Network Theory has said relatively little about gender, a related and particularly relevant set of points are made by Haraway, initially in her highly influential 'Manifesto for Cyborgs' (1981/1991). For Haraway, the cyborg served as an epistemological and ontological trope for anti-essentialism, breaking down boundaries and insisting on combinations, ambivalence, particularity and intersectionality both in relation to categories of race, class, gender, age (and so on) and, more specifically, in relation to human/non-human relations, challenging any clean distinctions between organism and machine. Here the 'cyborg' offers a representation of the socio-material nature of everyday life, an insistence on the co-constitution of artefacts and human existence in the information society. This focus on materiality chimes with recent calls in critical gerontology to bring the body back into ageing in non-essentialist ways (Twigg 2004): to recognise the materialities of ageing bodies and embodiment as well as their social and cultural construction (Calestani and Slevin 2006) and explore both perceptions and lived experiences (Ennals and Salomon 2011). Putting this in more theoretical terms, Haraway (1991) refers to the 'apparatus of bodily production', linking discourse, actions - both human and non-human - with 'matter', described as a 'witty agent' (p.199) that 'matters' (Barad 2003) beyond only the interpretations that we place on it.

Drawn together, these insights from feminist theory, critical gerontology and STS suggest a disassembling of the self in relation to understanding gendered ageing: shifting our focus from individuals to cyborg practices in particular organizational settings. Following this line of argument, we suggest that exploring relations between gender, age and new technologies at work 
means looking for the spaces, places and times where gendered ageing appears as more or less problematic and understanding the processes that produce these outcomes. To do this we draw further on Staunæs' (2003) who adopts the performative and undetermined principles of intrasectionality, to suggest that '... the concrete doings and intermingling of categories' ( $\mathrm{p}$.105) may result in both 'troubled' and 'untroubled' subjects (see Wetherall 1998). In this sense, 'subjects' refers not to discrete individuals, but to the discourses and practices that intersect in particular contexts to make particular positions comfortable, normal and unquestioned or, alternatively '... inappropriate, destabilized, difficult: where they are challenged and must be repaired' (Staunæs' 2003; 104). More specifically, to focus on our topic here, we suggest that gendered ageing may appear as more or less troubled in particular circumstances.

\section{Case and Methodology}

As many others have noted, nursing as a profession cannot be understood outside of its constitution in gendered terms, as feminine: linked to feminised constructions of caring, intimacy and body work (Hunter 1988; Jolley and Brykczynska 1995; Davies 2003) and as 'other' to medicine, which has been constructed as masculine, and hierarchically superior to nursing (Stein 1967; Porter 1995). In this sense, 'doing nursing' is 'doing gender' (Butler 1990; 2004), although this is not deterministic or homogenous, and has been challenged - for example - in the professionalising strategies of nursing that have sought autonomy from medicine (Witz 1992); and in particular spaces of nursing practice, often the more technologically intense specialities and performances of masculinity within these (Author 2006). Nonetheless, as Sandelowski (2000) has shown in her excellent history of US nursing, the history of nursing practice has been entwined with machines and tools since at least the 1930s: from thermometers, drips and ventilators to telephones, monitors and computers, nurses depend on these devices to do their work (Sandelowski 2000). To draw on Haraway (1991) we can see nursing as a 'cyborg practice', albeit that this has been contested at various points often in specifically gendered terms, casting '... nursing as a female culture at odds with masculine technology' (Sandelowski 2000; p.9).

Hence, healthcare appears as an excellent field for studying gendered ageing at work, not the least because of the profound technological changes that are underway linked to the introduction of digital technologies. Our overall aim is to explore how where and when gendered ageing produced in this context. In what follows we discuss the findings of a three-year research project 2009-12, funded by the Research Council of Norway under the Sykefravær (sickness absence) research programme ${ }^{1}$. In common with many other European countries, long term sick leave and early retirement are endemic in the Norwegian healthcare sector (Barmby et al 2012; Stapelfeldt et al 2013) and the partners in the 'tripartite agreement' (between state, unions and employers) are concerned to implement their 'inclusive work life agreement' not least to enable people to stay in employment longer into older age (Ennals and Salomon 2011). Given that previous research suggests a strong relationship between technical innovation, sickness and early retirement, our study aimed to explore if and how this might be related to the rapidly transforming digital landscape of healthcare.

\footnotetext{
${ }^{1}$ Thanks to the Research Council of Norway for funding the project: "Ageing healthcare workers and ICT. Making healthcare workplaces healthy for 50+", project number 193606.
} 
Our methodology focused on two case studies of large University hospitals and included 55 indepth interviews with key informants (managers, trade unionists, HR and IT personnel) and healthcare professionals. In key informant interviews we concentrated specifically on issues related to older workers, but with the older workers we concentrated on work-life histories, designed to capture change over time and allow the participants to make links between the different aspects of their daily lives and life-times (for example, between work and home life). We did not focus specifically on categories of gender or age in our questions, preferring to see if and how these appeared in the narratives of our doctors and nurses. Interviews were conducted in a mixture of Norwegian and English (the Norwegian excerpts used in this paper were translated by the research team). In common with all verbal accounts, these data depend on the themes that individuals were willing to discuss with us and, as always, this may offer only a partial account. What people say in interviews and what they think, say elsewhere or do may be different. However, our initial attempts at using observational methods proved disappointing: watching the flow of action in a hospital it is almost impossible to distinguish gender/age/technology relations specifically. Other methods, for example asking participants to produce diaries or visual narratives, might produce relevant data here but were beyond the scope of this project for a range of practical and ethical reasons.

Our data were thematically analysed. Interview transcripts were discussed in detail by the team and themes were developed collectively, both deductively in relation to the core research questions of the project (how do older healthcare workers respond to the increasingly technical workplace?) and inductively from the empirical data. Our theoretical framework developed iteratively through repeated readings of related literature and the empirical data; and informed our ongoing empirical analysis. The study was approved by the Norwegian Social Science Data Services and reported (as required) to the Regional Committee for Medical Research Ethics. In this paper we draw mainly on our in-depth interviews with nurses over 50 years old, specifically those who had continued working in clinical practice well into older age. All were women, not by design but reflecting the sex-segregated recruitment of earlier years. We also draw on our interviews with older doctors, both women and men.

In what follows we apply the theoretical framework elaborated above to explore the situated, contingent and dynamic intrasectionalities of gendered ageing as these emerge in hightechnology healthcare environments. Here we find multiple and contradictory outcomes: we find specific places, spaces and times where gendered ageing is articulated as troubled in relation to technology. But we also find instances where there appears to be an untroubled relation between technological innovation and gendered ageing. We present the contradictory outcomes and discuss how we may account for the differences.

\section{Troubled Intrasections}

\section{This job is not for old women. It doesn't fit.}

(Anna, Assistant Nurse)

Where gendered ageing appeared as a troubled position in relation to technological innovation, it did so at the in the interplay of a number of historical conditions and contemporary processes with particular individual circumstances. As we have argued above, this is not about gender 
and/or age per se, as fixed or independent categories, but about the conditions that produce intrasections of these in everyday practice. In this empirical field, older nurses' stories of everyday experience pointed to the broader policy and politics of organizational change in the Norwegian healthcare system as important to the emergence of gendered ageing. In Norway, like the UK and other Western countries, the healthcare sector has been subject to substantial ongoing phases of organizational change both in general (new forms of managerialism for instance) and specifically in terms of technological innovation:

There are big expectations from the government, not to mention wider society, about the future of ICT in bealthcare. (Tone, Nurse)

The development runs faster and faster. We get new machines all the times. (Rønnaug, semi-retired Nurse)

This becomes problematic when combined with a sense of powerlessness in relation to change:

It's the people far above us in the organization who determine our working day. They cannot turn a baby in an incubator, far less teach a baby to eat, but they can decide what we do. (Astrid, Nurse)

Similarly, the work that Karin had trained for as a theatre nurse - sterilising and preparing instruments, calculating drug doses and playing an active part in operations themselves - is no longer necessary. Pre-packed surgical kits, pre-dosed drugs and keyhole surgery make these skills redundant. Organisational change, outsourcing and new technologies produce discharge lifelong experience. Now:

You hang around and watch. It has become a different boring job ... [for instance] it is tiring with endoscopy because you bave nothing to do - you just stand there. (Karin, Nurse)

At the same time, new work tasks, particularly regarding patient record keeping in electronic systems demand new skills, and more importantly 'clerical' skills that these nurses find it hard to identify with:

I've said that I will not use it ... I'd rather spend time on something else - useful - instead of sitting in front of a screen. (Karin, Nurse)

Karin does not find the computer useful for her work. It is not included in the cyborg practices that she enjoys, so she does not see the point in spending time learning it and using it. It is not technology per se that is the problem, but a particular intrasection of this technology that demands cyborg practices that are dissonant with Karin's embedded experience and her professional identity as a nurse. It is also the pace with which this new technology has been introduced, and the lack of control that these nurses have over the changes, combined with lack of support in this landscape of change, that makes these conditions troublesome for nurses. One key factor is training:

We just had to jump into it, without much training. They showed us in the Thursday meeting when we got the new rack. Everybody knew the old one, so of course we got a new one. And when we were standing there and did not know, we had to see if the nurse who had been trained, and more or less mastered it, was free and could come and help. (Rønnaug, semi-retired Nurse) 
Nurses, who were once highly competent and used to being the expert, were made ignorant and dependent on the few who had been trained, sometimes with profound effects:

That's where I jumped off! It was only two years until I was about to be retired - and when I saw all the gadgets I felt ... one should not feel that as long as one is working, but ... now, now I start to feel old. (Solveig, retired Nurse)

Similar effects were produced by the organization of nursing work more generally. This is hard physical work: long shifts, night-work, a lot of standing, walking, lifting, even running and few breaks or chances to leave the ward. One of the major causes of sick-leave amongst nurses is musculoskeletal problems (Horneij et al 2004; Clews 2009): the body can 'let you down' - not because of being old, or female, per se - but because the work is hard and embodied materialities cannot always be 'mastered' (Haraway 1991):

... constantly being forced to "take one more night shift" ... is so difficult when your body does not want it. The body just will not. (Hege, ex-Nurse)

In short, we are suggesting that gendered ageing appears indirectly through the organization of nursing work. We say indirectly, because it is the gendered nature and status (or relative lack thereof) of the profession that contributes to the emergence of ageing here. This point is underscored below, where we consider the different arrangements made for doctors as their experience is mediated by a profession with greater power and status, linked not least to its gendered history.

First though, we turn our attention to the more direct emergence of gendered ageing as it appears through the intersecting materialities of sexed and gendered bodies and technologies, which may make the cyborg practices of nursing work harder still:

.... the nebuliser, it makes a soft and whooshing sound. Once the parents of a child said 'what a terrible noise' and I understand that. It has destroyed a piece of me. When I'm in private I cannot stand hearing the bumming of a refrigerator or a computer. I said to my partner, you have no idea what those sounds bave done to me. I just want to get away from them. (Ingvild, Nurse)

The practice of technology is embodied but this may be more or less visible: at times naturalised and unarticulated; at others jarring and uncomfortable. Trine explains this specifically in relation to the sexed aging body:

I am in menopause so I start sweating when I get stressed. This is very uncomfortable when I stand close to the families (around the incubator) [...] during the last years I got the feeling that I did not see very well. I could not see details and that was irritating. Neither could I localise the alarms on the monitors as easy as before. I become very tired. (Trine, Nurse)

Troubled gendered ageing may result from these particular cyborg practices. Keeping up with the pace of technical innovation can also take a lot of time and energy and specifically aged gendered divisions of labour can make these difficult to find. For nurses combining care for small children or elderly parents - whatever their age - lacking the time to 'keep up' can be cast by others as a gendered lack of capacity for technology, whilst fear of 'losing the grip' on technology may make age appear. As Hege said when she did not have time to learn a new system and her manager 
complained: 'then I felt like a hopeless old woman'. Or, to put it more directly still: then gendered ageing appeared as a troubled category.

Our argument so far is that there is nothing inherent in gender, age or technology per se but rather that gendered ageing appears as troublesome under particular conditions. So far we have seen that gendered ageing may become troubled at the intersection of professional and organizational processes, dynamic work-life relationships across the life course and materialities in daily working practices. In the cases that we have considered so far, gendered ageing appears both directly - linked to gendered/aged divisions of labour and to the sexed/ageing body - and indirectly - via the organization of nursing as a gendered profession. In what follows we substantiate our argument by turning to stories about untroubled gendered ageing in healthcare work.

\section{Untroubled Intrasections}

We found many examples where new technologies were seamlessly integrated by older nurses. The particular circumstances of these individuals' working lives share some similarities with those discussed above but differ in some important respects such that gendered ageing does not appear as a troubled category, even where technological innovation is high:

We have some, yes actually quite many over 50 bere and I think they are very good at keeping up. They are not so concerned or engaged in the technical but they master it very well. They see that you have to because you have to act quickly, and they see the necessity of it, but they use it more like a tool, whereas they still manage to see: they look at the patient also, they do not only see the technical ... and that is the difference from the less experienced nurses who can be too engaged in the technical. (Grete, Head Nurse, Intensive Care - key informant)

In these cases, the gender-age-technology relation remains untroubled. Here lifelong experience - not named as age - is an important ingredient in the cyborg practices of nursing. Trine explains:

There are so many tubes coming out of the body and inexperienced nurses don't dare to touch the patient. They are afraid the tubes will fall out, but caring for little babies - they need a lot of contact. We have to bold them underneath and hold the [tracheotomy] tube and keep an eye on all the other equipment as well. (Trine, Nurse)

Her then, the nursing cyborg is untroubled: new devices are not something 'other' to the work and are accommodated easily into familiar discourses of nursing work in this field.

A patient's condition can become critical very quickly. A good nurse cannot be afraid of making mistakes or even of death. To be that nurse you need compassion and technical skills. (ibid)

Indeed, here nursing 'experience' strengthens the cyborg, and these older nurses feel at ease with their job. However, it is notable that experience appears as wisdom and competence, rather than a positive representation of age, which remains unarticulated. And, to repeat a point made in the previous section, the process of accommodation requires time, effort and appropriate training. On this ward, regular meetings were scheduled to support the integration of new technologies into practice. 
We also noted a particularly interesting phenomenon amongst several nurses who had left bedside nursing work - Hege, Trine and Ingvild above - citing difficulties with the scale and pace of technological change as well as the intersecting materialities of ageing bodies and new technologies. These individuals had all moved on to work for the hospital's Information Technology Department, doing highly technical work with the new electronic patient record system. Trine describes this transition:

I went into this [new] job very positive, ears open, and asking, and searching and have got a fantastic reception and I have been very lucky. I have got a super boss, good introduction and I have had time to dive and dive and dive and I am on my way ... I have climbed the competence ladder like a fire ladder. (ibid)

So whilst her departure from nursing might well have been interpreted as evidence of incompatibility between gendered ageing and new technologies, it becomes clear that gendered ageing in highly technical work might be troublesome or untroublesome, depending on the conditions, even for the same individual. It is not particular categories of self that produce gendered ageing but material circumstances, organizational processes and discourses in particular settings.

Our point is elaborated if we turn to consider older medics. Doctors too - of course - have had to accommodate swathes of new technologies in their daily work and there is certainly some evidence of older medics struggling to do so in particular settings. Mari, a consultant with 30 years' experience explained:

I think there are two kinds of older doctors: those who, in a sense, have followed the technological developments and who have mastered these things very well; and those who do not master these things because it has not been a big part of their lives. And still there are some here, among the older doctors, who struggle with using email and have problems with PowerPoint presentations and those things that we are expected to manage. (Mari, Consultant)

However, she tells us, this is not recognised as a problem or professional weakness. Indeed early retirement is relatively rare in medicine, compared with nursing:

I know that many leave nursing quite early in their career because it's such hard work... Amongst the doctors its very common to work to 67 or 70 or longer... I have never thought that doctors retire early. (ibid)

How can we explain this difference? First, medical work is organized differently, with more support staff, reflecting the gendered status and hierarchical positioning of medicine. Mari explains that even those who face difficulties:

... manage with the help of the support personnel and that might include other colleagues but to a large degree it is the office personnel who know the systems. (ibid)

Doctors in this hospital can also refuse shifts, whereas this option is not open to nurses here: 
There have been quite a few doctors here who have not been willing to take shifts when they pass 60 and the agreement between the union and [the hospital] makes that possible, for them not to work shifts. (ibid)

In addition to flexibility and advantageous working conditions, there are distinctive frames of reference to explaining those cases where older doctors choose (and this appears as a choice, it seems) not to use new technologies. Nils, a senior doctor now in his late 40s, describes an older colleague, 67 years old:

He gave us a PowerPoint demonstration the other day, for the first time ... it had 1500 slides in it! 10 slides were great but he doesn't know how to edit. He knows that we know but that we don't say anything. (Nils, Consultant)(Our emphasis)

Rather than 'dinosaurs' these are the 'good old guys in danger of extinction' (Author 2010). The discourse of wisdom frames and explains the choices made by these older doctors. Consequently, it is possible to side-step the demands of new technologies without being cast as 'old' or 'past-it'. Indeed, emblematic stories circulate the hospital about a now retired senior manager, fondly remembered because he '... had this principle that he should never touch a memory stick or use a PowerPoint' (Mari, Consultant).

\section{Discussion and Conclusions}

At the beginning of this paper we asked: 'how, where and when is gendered ageing produced in a context of rapid technological change?' We argued that this is both a theoretical and an empirical question. How we 'see' gender, age and technology depends on the conceptual lenses that we use, particularly in relation to the ontological status of these categories and the relationships between them. We proposed a framework in which we conceptualise gendered ageing as intrasectional, contingently produced in particular circumstances and performative in nature. From this perspective, we explored the conditions where the gendered ageing appeared as more or less troubled, specifically in relation to the increasingly high technology landscape of hospital healthcare work.

The empirical analysis presented above demonstrates the affordances of this framework, showing that the intrasections of gender-age-technology may be more or less troubled, even for the same individual. Pushing beyond this observation, our data indicate that the key processes are shaped by gendered differentiation between the medical and nursing professions. We do not see these as inevitable or essentially gendered structures, but rather as the 'storing' of past agencies - actions by individuals, groups and the state - that 'activate' power differentials between medicine and nursing. These operate discursively, in terms of recognition of status, skill and authority and in more material terms through differences in working conditions, for example as older doctors are able to decline night-shifts, have support from clerical staff and a greater say in changes to their working practices. Our conceptual approach allows us to capture and interrogate this range of complex outcomes and, in this sense, we hope that it makes a helpful contribution to current debates about gender, age and technology particularly in the field of healthcare but also - perhaps - beyond, in the wider digital economy. 
However, we began our paper with some more political and policy orientated questions. What might our theoretical approach and empirical analysis mean in these more practical terms, specifically in the context of the coming crisis in the nursing workforce that will affect many Western nations over the next decade? Thus far we have seen relatively little policy response either at the level of government policies on healthcare workforce planning in this context or at a more local, organizational level (Victoria Department of Health 2010). Although, as we have shown, it is in particular organizational contexts that gendered ageing emerges as a problematic, the hospitals in our study had no strategic policies to address the issues involved. On the surface this reflects a certain clueless-ness, as one HR director told us 'we know what the dilemmas are but not what to do!'. Our research suggests that this is underpinned by a profoundly disembodied and ageless understanding of both work and the worker, reminiscent of Acker's 'abstract ideal worker' (Acker 1990). This is well illustrated by the comments of one senior manager who told us:

... the hospital cannot keep up with a bunch of 60-year-olds hanging around who just want to work day shift. The hospital is operated 24/7 and that means night shifts ... people come to the hospital to work, not to have breaks. (William, Senior Manager)

In other words, if anyone cannot work shifts, or needs extended breaks, they must leave, despite the pressing staffing issues facing healthcare. This is represented here in terms of age, although it could of course apply to a range of other workers wishing to do day shifts only. The presumption of disembodied capacity eclipses the development of an organizational language, let alone policy development or resources to address the issues of an ageing gendered workforce. But until this is actively pursued, any hope for managing the challenges facing healthcare services in the future may be in serious doubt.

To date, the burden of responding to instances of gendered ageing has been largely individualised. Our research found that the response from some has been to get out, whether through early retirement or by finding other jobs where gendered ageing becomes untroubled again. Others undertake individual coping strategies, or 'shadow work' (Biggs 2004), to maintain their place, for example by doing extra work at home to keep up with change or exercising more to keep the body fit for work. In short, by performing youth, older age becomes untroubled. Beyond this, our research suggests limit on the effectiveness of formal legislative or equal opportunities-type solutions to the issues raised by gendered ageing. As long as such initiatives rest on structural- and individualised understandings, they will do little to address gendered ageing. Whilst they might prevent overt cases of discrimination - especially if they can overcome the separation of gender from age - and provide a necessary context for more specific interventions, on their own they will not address the complex and contingent emergence of gendered ageing that we have described. Instead, our analytical framework and empirical analysis suggest another way of thinking as necessary for transforming gendered ageing at work from troubled to untroubled intersections, and hence, maintain a healthy (older) workforce.

First, there needs to be a good understanding of the conditions that produce troubled and untroubled gendered ageing in particular settings. Because we no longer can identify 'pure' categories but must treat them as co-constitutive, we should think about working practices, rather than individuals with certain attributes, and see them as 'cyborg practices' that are transformed as a result of a changing interplay between organisational, technological and bodily 
aspects. Troubled gendered ageing should thus be seen as the outcome of such practices rather than the inherent attributes of individuals or inevitable consequence of reified structures that determine the actions of individuals. Consequently, political initiatives cannot be formed according to ideas about fixed structures and inequalities but need to take into account that working practices are performative and hence dynamic. Troubled gendered ageing is a product of certain changes in 'cyborg practices'. Drawing on Staunæs (2003) again, we must 'wait and see' what the outcomes actually are.

From this follows the second point, namely that there need to be local managerial flexibility in responding to instances of troubled gendered ageing. The only effective practices that we found in our research involved ward level managers, who were making 'below the radar' innovations to ensure that they could in post those older staff who were experiencing what they described as ageing. Using shorter shifts, allowing daytime-only rotations, allocating work tasks flexibly were all mechanisms in use and appeared to work in practice. Effective measures will not (only) be about 'tick-boxes' - which more bureaucratic guidelines can sometimes be reduced to - but should also allow creative and contextual problem solving.

This links to our third point: a request for further research. In our research we encountered several examples where ward-level managers (nurses) had found room for manoeuvre in the management of older nurses, for example manipulating the rotas to minimise night shifts or maximise the particular skills of more experienced nurses with attention to the physical and wider well-being of these staff. These interventions were in notable contrast to senior management insistence on the ageless, disembodied worker yet at the same time produced positive effects in retention and staffing security at ward level. This suggests the need to explore such employee driven innovations and the contribution that they might make towards addressing the significant challenges facing healthcare workforce management now and in the future.

Overall our approach insists that theoretical innovation and practical interventions go hand in hand. Understanding the complexities of gendered ageing, here in a context of rapid technological change but also more widely, demands that we move beyond received wisdoms and assumptions about gender, and age and technology. Learning to see if and how these become troubled in their intra-actions, as well as where they do not offers grounds for constructive initiatives to support and promote longer working lives whilst, conversely, learning from change 'on the ground' - how this does, and doesn't take place - will add to our understandings of the multiple and dynamic intrasectionalities of gendered ageing.

\section{REFERENCES}

Author 2006

Authors 2009

Authors 2010

Acker, J. (1990) 'Hierarchies, jobs bodies: a theory of gendered organization' Gender and Society 5, pp. 390-407.

Adam, AE, Griffiths, M, Keogh, C, Moore, K, Richardson, H and Tattersall, A (2006) 'Being an 'it' in IT: gendered identities in IT work' European Journal of Information Systems 15 (4) pp. 368378. 
Arber, S., Davidson, K., and Ginn, J. (2003) 'Changing approaches to gender and later life' in Arber, S., Davidson, K., and Ginn, J. (Eds) Gender and Ageing: changing roles and relationships Maidenhead, Open University Press.

Aubert, P., Caroli, E., \& Roger, M. (2006) 'New technologies, organization and age: firm level evidence' The Economic Journal 116, pp.73-93.

Barad, K. (2003) 'Posthuman performativity: towards an understanding of how matter comes to matter' Signs 28(3) pp.801-31.

Barmby, T., Ercolani, M., and Treble, J., (2012) 'Sickness absence: an international comparison' The Economic Journal 2002 (112): F315-333

Bartel. A., \& Sicherman, N. (1993) 'Technological change and retirement decisions of older workers' Journal of Labour Economics 11(1), pp. 162-183.

Biggs, S., (2004) 'Age, gender, narratives and masquerades' Journal of Aging Studies 18, pp. 45-58. Brooke, L. (2009) 'Prolonging the careers of older IT workers' Ageing and Society 29(2) pp. 237256.

Butler, Judith (1990) Gender Trouble: Feminism and the Subversion of Identity New York: Routledge. Butler, Judith (2004) Undoing Gender New York; London: Routledge.

Calestani, T. and Slevin, K. (2006) Age Matters: realigning feminist thinking New York, Routledge. Chartered Institute of Personnel Development (2012) Managing a Healthy Aging Workforce: a national business imperative London, CIPD.

Cockburn, C. (1985) Machinery of Dominance London, Pluto.

Davies, K. (2003) 'The body doing gender: the relations between doctors and nurses in medical work' Sociology of Health and Illness 25 (7) pp.720-742.

Department of Health (2002) Delivering 21st Century ICT Support for the NHS London, HMSO.

Department of Health (2011) Innovation, Health and Wealth: accelerating adoption and diffusion in the NHS London, HMSO.

Dowd, J. and Bengston, V. (1978), 'Aging in Minority Populations: An Examination of the Double Jeopardy Hypothesis' Journal of Gerontology, 33, 427-36.

Duncan, C. \& Loretto, W. (2004) 'Never the right age? Gender and age-based discrimination in employment' Gender, Work and Organization 11(1) pp.95-115.

Ennals, R., and Saloman, R., (2011) Older Workers in a Sustainable Society Berlin, Peter Lang. Eriksson-Zetterquist, U., and Knights, D. (2004) 'Stories about men implementing and resisting new technologies' New Technology, Work and Employment 19 (3) pp. 192-206.

Evandrou, M. and Glaser, K. (2007) Changing Economic and Social Roles in Mid-life in Britain

Discussion Paper no. 0701, University of Southampton, Centre for Research on Aging.

Featherstone, M. and Hepworth, M. (1983) 'The midlifestyles of George and Lynne' Theory,

Culture and Society 1, pp.85-92.

Friedberg, L. (2003) 'The impact of technological change on older workers: evidence from data on computer use' Industrial and Labour Relations Review 56(3), pp. 511-529.

Clews, G. (2009) 'NHS stress driving up nurse sick leave levels'

http://www.nursingtimes.net/nursing-practice/clinical-zones/occupational-health/nhs-stressdriving-up-nurse-sick-leave-levels/5000401.article\# Accessed 12/11/13

Haraway, D. (1991) Simians, Cyborgs and Women: The Reinvention of Nature New York, Routledge. Hornjeij, E., Jensen, I., Holmstrom, E., and Ekdahl, C., (2004) 'Sick leave amongst home care personnel: a longitudinal study of risk factors’ BMC Musculoskeletal Disorders 5 (38) 
Hunter, K. (1988) 'Nurses: the satiric image and the translocated ideal' in Jones, A. (Ed) Images of Nurses: perspectives from History, Art and Literature Philadelphia, PA, University of Philadelphia Press pp.113-127.

Irni, S. (2009) 'Cranky old women? Irritation, resistance and gendering practices in work organizations' Gender, Work and Organization 16, 6 pp.667-683.

Jolley, M. and Brykczynska, G. (Eds) Nursing: beyond tradition and conflict London, Mosby. Joseph Rowntree Foundation (2003) Nurses over 50: options, decisions and outcomes The Policy Press, Bristol

Joyce, K. and Mamo, L. (2006) 'Graying the Cyborg' in Calestani, T., and Slevin, K. (2006) Age Matters: realigning feminist thinking New York, Routledge

Krekula, C. (2007) 'The intersection of age and gender: reworking gender theory and social gerontology' Current Sociology 55(2), pp. 155-171.

Krekula, C. (2012) 'From double jeopardy to institutionalized age codings: on gendered age relations in the Swedish fire services' paper presented at the Gender, Work and Organization Conference, 27-29 June 2012, University of Keele Latour, B. (2005) Re-assembling the Social: an introduction to actor network theory Oxford, Oxford University Press.

Loretto, W., Vickerstaff, S. and White, P. (2005) Older workers and options for flexible work, Manchester: Equal Opportunities Commission

Lykke, N. (2010) Feminist Studies: a guide to intersectional theory, methodology and writing London, Routledge.

Mackenzie, D., and Wajcman, J. (Eds) (1999)The Social Shaping of Technology Basingstoke, Open University Press.

McCall, L. (2005) 'The complexity of intersectionality' Signs 30(3) pp. 1771-1800.

McMullin, J. (2000) 'Diversity and the State of Sociological Ageing Theory' The Gerontologist 40(5) pp.517-530.

McMullin, J. and Berger, E. (2006) 'Gendered ageism/Age(ed) sexism: the case of unemployed older workers' in Calestani, T., and Slevin, K. (2006) Age Matters: realigning feminist thinking New York, Routledge.

Moore, S. (2009) "No matter what I do I would still end up in the same position": age as a factor defining older women's experience of labour market participation' Work, Employment and Society 23(1), pp. 655-671.

Norweigan Ministries, 2012 Digitizing Public Sector Services: Norwegian e-Government Program Oslo. Nyberg, D. (2009) 'Computers, customer service operatives and cyborgs: intra-actions in call centres' Organization Studies 30, 11 pp.1181-99

Phillipson, C. and Smith, A. (2005) Extending Working Life: a review of the research literature Research Report 299, London, Department for Work and Pensions.

Parliamentary Office of Science and Technology, 2011 An Ageing Workforce POST, London. Porter, S. (1995) Nursing's Relationship with Medicine Aldershot, Avebury.

Robertson, A. (2000) "II saw the handwriting on the wall”: shades of meaning in reasons for early retirement' Journal of Aging Studies 14(1), pp. 63-79.

Sandelowski, M. (2000) Desires and Devices: gender, technology and American nursing Chapel Hill, NC., University of North Carolina Press.

Søndergard, D. (2005) 'Making sense of gender, age and disciplinary position: intersecting discourses in the academy' Feminism and Psychology 15(2) pp.189-208. 
Staunæs, D. (2003) 'Where have all the subjects gone? Bringing together concepts of intersectionality and subjectification' NORA 2(11), pp. 101-110.

Stapelfeldt, C., Nielsen, C., Andersen, N., Krane, L., Fleten, N., Borg, V., and Jensen, C., (2013) 'Are environmental characteristics in the municipal eldercare, more closely associated withfrequent short sick leave spells among employees than with total sick leave: a cross-sectional Study' BMC Public Health 2013;13(1):578.

Smith, O. 2012, 'The invisiblity of older women's experiences of equality: intersectionality, vulnerability and the limits of antidiscrimination' paper presented at the Gender, Work and Organization Conference, 27-29 June 2012, University of Keele.

Stein, L. (1967) 'The doctor-nurse game’ Archives of General Psychiatry 16, pp.699-703.

TUC, 2013 Older Women and the Labour Market London, TUC.

Twigg, J. (2004) 'The body, gender, and age: Feminist insights in social gerontology' Journal of Aging Studies, 18 59-73.

Victoria Department of Health (2010) V alue added: the wisdom of older nurses at work. Melbourne, Victoria Department of Health.

Wacjman, J. (2004) Technofeminism Oxford, Polity Press.

Wetherell, M. (1998) 'Positioning and interpretive repertoires: conversations, analysis and poststructuralism in dialogue’ Discourse and Society 9(3) pp.347-412

Witz, A., (1992) Professions and Patriarchy London, Routledge.

Wolkowitz, C. (2006) Bodies at Work London, Sage. 